\title{
Prevalence of Clinical Signs and Symptoms of Hypertension: A Gender and Age Based Comparison
}

\author{
Hafsa $\mathrm{K}^{1}$, Ahsan $\mathrm{AS}^{2}$, Summaiya $\mathrm{I}^{3}$, Zarghoona $\mathrm{W}^{4}$, Sana $\mathrm{N}^{5}$, Maham $\mathbf{R}^{6}$, Uroosa $\mathrm{S}^{7}$, Faiza $\mathrm{J}^{8}$, Anum $\mathrm{G}^{9}$, \\ Adnan $\mathbf{A}^{10^{*}}$ \\ ${ }^{1}$ MBBS, Resident Emergency Medicine, King Fahad Specialist Hospital \\ ${ }^{2}$ MBBS, Msc Public Health, Specialist Family Medicine, Ministry of Health, Riyadh \\ ${ }^{3}$ MBBS, Hamdard College of Medicine and Dentistry, Hamdard University Hospital \\ ${ }^{4}$ MBBS, M. Assistant, Musavvir Stem cell Clinic and Pathology Laboratory \\ ${ }^{5}$ MBBS, MPH, Assistant Professor, Department of Community Medicine, Avicenna Medical College \\ ${ }^{6}$ MBBS, Senior Medical officer, Community Health Services \\ ${ }^{7}$ MBBS, House Officer, Liaquat National Hospital \\ ${ }^{8}$ Pharm D, Hamdard University \\ ${ }^{9}$ MBBS, Medical Officer, Ashfaq Memorial Hospital \\ ${ }^{10}$ MBBS, M.Phil, Senior Lecturer Department of Physiology Al-Tibri Medical College Karachi
}

Received: April 06, 2018; Accepted: April 20, 2018; Published: April 27, 2018

*Corresponding author: Adnan Anwar, MBBS, M.Phil, Senior Lecturer, Department of Physiology, Altibri Medical College Karachi, Pakistan.E-mail: anwaradnan32@gmail.com

\begin{abstract}
Objective: To compare the prevalence of clinical signs and symptoms of hypertension among different gender and age based groups of hypertensive patients.

Materials and Methods: A cross-sectional study was conducted with 372 patients aged 18 or above with self-reported history of hypertension and on anti-hypertensive medication. It was a multicenter study performed in urban health center and Myanmar health center for duration of 6 months from June 2017 till November 2017. Hypertension associated signs and symptoms were evaluated with the help of a questionnaire and clinical examination. Blood pressure was measured using sphygmomanometer with stethoscope.

Results: A higher percentage of males were smokers (18.2\% vs. $1.4 \%)$ and gave a positive history of chest pain (49.3\% vs. $38.2 \%)$, though a higher percentage of females gave a positive history of vision problems ( $57.0 \%$ vs. $49.3 \%)$, fatigue $(74.8 \%$ vs. $70.3 \%)$ and confusion (66.7\% vs. $60.6 \%)$. Moreover, a higher percentage of $\leq 40$ years old patients gave a positive history of headache $(80.7 \%$ vs. $69.4 \%)$ though a higher percentage of $>40$ years old patients were smokers ( $12.0 \%$ vs. $4.7 \%$ ), gave a positive history of vertigo $(59.3 \%$ vs. $47.7 \%)$, chest pain $(49.3 \%$ vs. $32.2 \%)$, vision problems ( $57.4 \%$ vs. $44.2 \%)$, dyspnea ( $57.4 \%$ vs. $43.8 \%$ ), increase in urinary frequency ( $45.5 \%$ vs. $30.6 \%)$, nausea $(25.4 \%$ vs. $20.5 \%)$, sleep apnea (38.6\% vs. $20.5 \%$ ), irregular heartbeat/palpitation (39.9\% vs. $33.0 \%$ ), fatigue $(74.8 \%$ vs. $67.0 \%)$ and confusion $(68.6 \%$ vs. $52.3 \%)$.

Conclusion: The prevalence of smoking, chest pain, vision problems, fatigue and confusion were found to be different between both genders. Furthermore, the prevalence of smoking, headache, vertigo, chest pain, vision problems, dyspnea, increased urinary frequency, nausea, sleep apnea, irregular heartbeat/palpitation, fatigue and confusion were found to be different between both age groups.
\end{abstract}

Key words: Prevalence; Signs and Symptoms; Hypertension; Gender; Age

\section{Introduction}

Hypertension is regarded as an important public health challenge worldwide because of its high prevalence. [1,2] It is known to increases the risk of various medical conditions such as heart attack, stroke, kidney failure and blindness. [3] The
Comparative Risk Assessment Collaborating Group has identified hypertension as the third leading risk factor for morbidity and as the leading risk factor for mortality worldwide. [4] More than a quarter of the world's adult population has been reported to suffer from hypertension, two thirds of which belong to developing countries. [5]According to World Health Organization 
estimates, hypertension annually results in 7.5 million deaths. [3]

An analysis of global data revealed that the overall prevalence of hypertension is similar in both genders, and that it consistently increases with age worldwide. [5] A meta-analysis earlier reported $17 \%$ of the Pakistani population to be suffering from hypertension. [6] The World Health Organization recently estimated that $25.2 \%$ of the Pakistani population had high blood pressure. [7]

Hypertension is defined as a systolic blood pressure of $\geq 140 \mathrm{~mm} \mathrm{Hg}$, or a diastolic blood pressure of $\geq 90 \mathrm{~mm} \mathrm{Hg}$, or taking antihypertensive medication. [8] Hypertension can be of two types, essential and secondary. Essential hypertension can be defined as a rise in blood pressure of unknown cause that increases risk for cerebral, cardiac, and renal events. [9] Secondary hypertension is defined as increased systemic blood pressure due to an identifiable cause. [10]

Multiple factors such as age, gender, and level of high blood pressure can influence the way in which hypertension presents itself clinically but literature does not reveal substantial relevant data, both internationally and locally, making the task of assessing the effects of above mentioned factors in the clinical manifestation of hypertension difficult. Our objective therefore was to compare the prevalence of clinical signs and symptoms of hypertension among different gender and age based groups of hypertensive patients.

\section{Materials and Methods}

After taking ethical approval, a cross-sectional study was carried out among patients with self-reported history of hypertension and on anti-hypertensive medication. It was a multicenter study performed in Urban health center and Myanmar health center for a duration of 6 months from June 2017 till November 2017. By employing convenient sampling technique, a total of 372 patients aged 18 or above were included in the study. Patients with history of diabetes, cardiac events, neurological disorders, cluster headache, gastrointestinal disease, visual problems, epistaxis before being diagnosed with hypertension and morbid obesity were excluded from the study.

A detailed history was taken from each patient about hypertension associated symptoms with the help of a structured questionnaire. The questionnaire was designed based on 12 major or most frequently encountered symptoms by the hypertensive patients. The site, duration, and severity of each symptom were documented. Each symptom was graded from mild to severe to assess the severity of the symptoms. The presence of edema was noted with its laterality and grading. The appearance of chest pain was noted with its severity. The problems of vision were noted and classified according to the loss in field of vision. The history of epistaxis and urinary symptoms were noted with frequency. Few additional symptoms such as nausea, sleep apnea, palpitations, fatigue and confusion were also assessed subjectively. Blood pressure was measured using sphygmomanometer with stethoscope to assess hypertension level.

The collected data were coded, entered and analyzed on SPSS version 20 . The descriptive analysis was performed by calculating means and standard deviations for continuous variables and frequencies and percentages for categorical variables. The duration of study was 6 months.

\section{Results}

The total data collected were of 372 patients but after excluding missing data for various study variables the final data analyzed were of 303 patients for gender wise comparison and of 299 patients for age wise comparison.

For gender wise comparison, the study results revealed that the mean age of male patients was slightly higher than that of female patients $(50.36 \pm 11.93$ years vs. $46.74 \pm 12.93$ years) and therefore a higher percentage of them was above 40 years of age $(79.9 \%$ vs. $60.0 \%)$. An almost equal percentage of both males and females had systolic hypertension $(68.0 \%$ and $65.9 \%$ respectively) though the percentage of diastolic hypertension was slightly higher in females (53.1\% vs. $48.1 \%$ ). Both males and females had similar mean systolic blood pressure (141.13 $\pm 13.94 \mathrm{~mm} \mathrm{Hg}$ and $141.67 \pm 15.35 \mathrm{~mm} \mathrm{Hg}$ respectively) though the mean diastolic blood pressure was slightly higher in females $(86.09 \pm 9.65 \mathrm{~mm} \mathrm{Hg}$ vs. $84.43 \pm 10.71 \mathrm{~mm} \mathrm{Hg})$. Both males and females had similar mean duration of hypertension as well (4.86 \pm 5.39 years and $4.78 \pm 5.39$ years respectively). A much higher percentage of males were smokers (18.2\% vs. $1.4 \%)$ though a slightly higher percentage of females gave a positive history of headache $(75.3 \%$ vs. $70.8 \%)$. The mean duration of headache was found to be equal in both males and females (1.96 \pm 0.75 years and $1.96 \pm 0.68$ years respectively) and the most common site of headache was similar in both genders as well i.e. complete headache $(37.0 \%$ and $26.6 \%$ respectively). A majority of males reported their headache to be of moderate intensity whereas a majority of females reported it to be of severe intensity (53.7\% and $41.4 \%$ respectively). An equal majority of both males and females gave a positive history of vertigo (55.0\% and 55.9\% respectively) and a majority of both genders reported it to be of mild intensity (60.4\% and $65.0 \%$ respectively).An almost similar percentage of both males and females were found to have edema ( $40.5 \%$ and $43.0 \%$ respectively), a very high percentage of which was bilateral in both gender ( $84.6 \%$ and $80.4 \%$ respectively). The grading of bilateral edema of an almost similar percentage of both males and females was found to be severe (35.0\% and 36.5\% respectively). A higher percentage of males gave a positive history of chest pain $(49.3 \%$ vs. $38.2 \%)$ though a higher percentage of females required a hospital visit for it to subside $(16.4 \%$ vs. $5.4 \%$ ). A higher percentage of females gave a positive history of vision problems $(57.0 \%$ vs. $49.3 \%)$ though the most common type of vision problem was dark spots in field of vision in both males and females ( $47.9 \%$ and $45.0 \%$ respectively). A similar percentage of both males and females gave a positive history of dyspnea (53.0\% and $52.7 \%$ respectively) and a majority of both genders reported it to be moderate in intensity ( $57.3 \%$ and $48.1 \%$ respectively). A very low percentage of both males and females gave a positive history of epistaxis (2.6\% and 3.5\% respectively). A slightly higher percentage of males reported an increase in urinary frequency $(44.0 \%$ vs. $38.3 \%)$ though a majority of both 
males and females reported the change to be moderate $(42.7 \%$ and $40.4 \%$ respectively). A slightly higher percentage of females gave a positive history of nausea (25.9\% vs. $22.1 \%)$ whereas a slightly higher percentage of males gave a positive history of sleep apnea (34.2\% vs. $32.0 \%)$. An almost similar percentage of both males and females gave a positive history of irregular heartbeat/ palpitation (38.3\% and $37.0 \%$ respectively) though a higher percentage of females gave a positive history of both fatigue (74.8\% vs. $70.3 \%)$ and confusion (66.7\% vs. $60.6 \%$ ) (Table 1$)$.

\begin{tabular}{|c|c|c|c|}
\hline \multirow{2}{*}{\multicolumn{2}{|c|}{ Variables }} & Males $(n=156)$ & Females $(n=147)$ \\
\hline & & Frequency $(\%) /$ Mean \pm S.D. & $\begin{array}{c}\text { Frequency }(\%) / \\
\text { Mean } \pm \text { S.D. }\end{array}$ \\
\hline \multicolumn{2}{|c|}{ Age (Years) } & $50.36 \pm 11.93$ & $46.74 \pm 12.93$ \\
\hline \multirow{2}{*}{ Age Group } & $\leq 40$ Years & $31(20.1)$ & $58(40.0)$ \\
\hline & $>40$ Years & 123(79.9) & $87(60.0)$ \\
\hline \multirow{2}{*}{ Systolic Blood Pressure } & Normotensive/ Prehypertensive & $50(32.0)$ & $50(34.1)$ \\
\hline & Stage 1/Stage 2 Hypertensive & $106(68.0)$ & $97(65.9)$ \\
\hline \multirow{2}{*}{ Diastolic Blood Pressure } & Normotensive/ Prehypertensive & $81(51.9)$ & $69(46.9)$ \\
\hline & Stage 1 /Stage 2 Hypertensive & $75(48.1)$ & $78(53.1)$ \\
\hline \multicolumn{2}{|c|}{ Systolic Blood Pressure (mmHg) } & $141.13 \pm 13.94$ & $141.67 \pm 15.35$ \\
\hline \multicolumn{2}{|c|}{ Diastolic Blood Pressure (mmHg) } & $84.43 \pm 10.71$ & $86.09 \pm 9.65$ \\
\hline \multicolumn{2}{|c|}{ Hypertension Duration (Years) } & $4.86 \pm 5.39$ & $4.78 \pm 5.39$ \\
\hline \multirow{2}{*}{ Smoking } & Yes & $28(18.2)$ & $2(1.4)$ \\
\hline & No & $126(81.8)$ & $142(98.6)$ \\
\hline \multirow{2}{*}{ Headache } & Yes & $109(70.8)$ & $110(75.3)$ \\
\hline & No & $45(29.2)$ & $36(24.7)$ \\
\hline \multicolumn{2}{|c|}{ Headache Duration (Years) } & $1.96 \pm 0.75$ & $1.96 \pm 0.68$ \\
\hline \multirow{4}{*}{ Site of Headache } & Temporal & $5(4.6)$ & $18(16.5)$ \\
\hline & Occipital & $27(25.0)$ & $24(22.0)$ \\
\hline & Frontal & $19(17.6)$ & $26(23.9)$ \\
\hline & Complete & $40(37.0)$ & $29(26.6)$ \\
\hline \multirow{3}{*}{ Intensity of Headache } & Mild & $25(23.1)$ & $28(25.3)$ \\
\hline & Moderate & $58(53.7)$ & $37(33.3)$ \\
\hline & Severe & $25(23.1)$ & $46(41.4)$ \\
\hline \multirow{2}{*}{ Vertigo } & Yes & $83(55.0)$ & $80(55.9)$ \\
\hline & No & $68(45.0)$ & $63(44.1)$ \\
\hline \multirow{3}{*}{ Intensity of Vertigo } & Mild & $52(60.4)$ & $52(65.0)$ \\
\hline & Moderate & $28(32.6)$ & $22(27.5)$ \\
\hline & Severe & $6(7.0)$ & $6(7.5)$ \\
\hline \multirow{2}{*}{ Edema } & Yes & $60(40.5)$ & $58(43.0)$ \\
\hline & No & $88(59.5)$ & $77(57.0)$ \\
\hline \multirow{2}{*}{ Laterality of Edema } & Bilateral & $44(84.6)$ & $45(80.4)$ \\
\hline & Unilateral & $8(15.4)$ & $11(19.6)$ \\
\hline
\end{tabular}




\begin{tabular}{|c|c|c|c|}
\hline \multirow{3}{*}{ Grading of Bilateral Edema } & Mild & $16(26.7)$ & $10(15.9)$ \\
\hline & Moderate & $23(38.3)$ & $30(47.6)$ \\
\hline & Severe & $21(35.0)$ & $23(36.5)$ \\
\hline \multirow{2}{*}{ Chest Pain } & Yes & $75(49.3)$ & $55(38.2)$ \\
\hline & No & $77(50.7)$ & $89(61.8)$ \\
\hline \multirow{3}{*}{ Severity of Chest Pain } & Improves with rest & $29(39.2)$ & $23(41.8)$ \\
\hline & Needs pain relieving medication & $41(55.4)$ & $23(41.8)$ \\
\hline & Requires hospital visit & $4(5.4)$ & $9(16.4)$ \\
\hline \multirow{2}{*}{ Vision Problems } & Yes & $75(49.3)$ & $81(57.0)$ \\
\hline & No & $77(50.7)$ & $61(43.0)$ \\
\hline \multirow{4}{*}{ Type of Vision Problem } & Loss of central vision & $7(9.6)$ & $5(6.3)$ \\
\hline & Loss of peripheral vision & $14(19.2)$ & $20(25.0)$ \\
\hline & Dark spots in field of vision & $35(47.9)$ & $36(45.0)$ \\
\hline & Pain in eyes & $17(23.3)$ & $19(23.8)$ \\
\hline \multirow{2}{*}{ Dyspnea } & Yes & $80(53.0)$ & $77(52.7)$ \\
\hline & No & $71(47.0)$ & $69(47.3)$ \\
\hline \multirow{3}{*}{ Intensity of Dyspnea } & Mild & $14(17.1)$ & $13(16.8)$ \\
\hline & Moderate & $47(57.3)$ & $37(48.1)$ \\
\hline & Severe & $21(25.6)$ & $27(35.1)$ \\
\hline \multirow{2}{*}{ Epistaxis } & Yes & $4(2.6)$ & $5(3.5)$ \\
\hline & No & $148(97.4)$ & $139(96.5)$ \\
\hline \multirow{2}{*}{ Increased Urinary Frequency } & Yes & $66(44.0)$ & $54(38.3)$ \\
\hline & No & $84(56.0)$ & $87(61.7)$ \\
\hline \multirow{3}{*}{ Change in Urinary Frequency } & Mild & $25(33.3)$ & $17(29.8)$ \\
\hline & Moderate & $32(42.7)$ & $23(40.4)$ \\
\hline & Severe & $18(24.0)$ & $17(29.8)$ \\
\hline \multirow{2}{*}{ Nausea } & Yes & $34(22.1)$ & $38(25.9)$ \\
\hline & No & $120(77.9)$ & $109(74.1)$ \\
\hline \multirow{2}{*}{ Sleep Apnea } & Yes & $53(34.2)$ & $47(32.0)$ \\
\hline & No & $102(65.8)$ & $100(68.0)$ \\
\hline \multirow{2}{*}{$\begin{array}{c}\text { Irregular Heartbeat/ } \\
\text { Palpitation }\end{array}$} & Yes & $59(38.3)$ & $54(37.0)$ \\
\hline & No & $95(61.7)$ & $92(63.0)$ \\
\hline \multirow{2}{*}{ Fatigue } & Yes & $109(70.3)$ & $110(74.8)$ \\
\hline & No & $46(29.7)$ & $37(25.2)$ \\
\hline \multirow{2}{*}{ Confusion } & Yes & $94(60.6)$ & $98(66.7)$ \\
\hline & No & $61(39.4)$ & $49(33.3)$ \\
\hline
\end{tabular}

For age wise comparison, the study results revealed that a higher percentage of patients in $>40$ years age group were males (58.6\% vs. $34.8 \%$ ). A higher percentage of $>40$ years old patients had systolic hypertension $(72.4 \%$ vs. $52.8 \%)$ though the percentage of diastolic hypertension was equal in both $\leq 40$ years and $>40$ years age groups $(49.5 \%$ and $50.0 \%$ respectively). Both the mean systolic and diastolic blood pressures were higher in $>40$ years age group $(142.85 \pm 14.44 \mathrm{~mm} \mathrm{Hg}$ vs. $137.69 \pm 14.70 \mathrm{~mm}$ $\mathrm{Hg}$ and $85.46 \pm 10.57 \mathrm{~mm} \mathrm{Hg}$ vs. $84.36 \pm 9.47 \mathrm{~mm} \mathrm{Hg}$ respectively). The mean duration of hypertension was higher in $>40$ years age group as well (5.66 \pm 5.78 years vs. $2.85 \pm 3.74$ years). A higher percentage of $>40$ years old patients were smokers $(12.0 \%$ vs. 
$4.7 \%$ ) where as a higher percentage of $\leq 40$ years old patients gave a positive history of headache ( $80.7 \%$ vs. $69.4 \%$ ). The mean duration of headache was found to be higher in $>40$ years old patients $(2.01 \pm 0.74$ years vs. $1.87 \pm 0.64$ years $)$ whereas the most common sites of headache were occipital and complete in both $\leq 40$ years $(27.5 \%$ each $)$ and $>40$ years age groups $(19.4 \%$ and $34.7 \%$ respectively).A majority of patients in both $\leq 40$ years and $>40$ years age groups reported their headache to be of moderate intensity ( $35.7 \%$ and $46.9 \%$ respectively). A higher percentage of patients in $>40$ years age group gave a positive history of vertigo $(59.3 \%$ vs. $47.7 \%)$ whereas a majority of patients in both $\leq 40$ years and $>40$ years age groups reported it to be of mild intensity (66.7\% and $61.8 \%$ respectively). An almost similar percentage of both $\leq 40$ years and $>40$ years old patients were found to have edema ( $40.2 \%$ and $42.6 \%$ respectively), a very high percentage of which was bilateral in both age groups $(76.7 \%$ and $84.6 \%$ respectively). The grading of bilateral edema of a majority of both $\leq 40$ years and $>40$ years age groups was found to be moderate ( $45.7 \%$ and $41.4 \%$ respectively). A higher percentage of $>40$ years old patients gave a positive history of chest pain $(49.3 \%$ vs. $32.2 \%$ ) though a higher percentage of $\leq 40$ years old patients required a hospital visit for it to subside $(22.2 \%$ vs. $6.9 \%)$. A higher percentage of $>40$ years old patients gave a positive history of vision problems (57.4\% vs. $44.2 \%$ ) though the most common type of vision problem was dark spots in field of vision in both $\leq 40$ years and $>40$ years age groups $(46.2 \%$ and $46.0 \%$ respectively). A higher percentage of $>40$ years old patients gave a positive history of dyspnea ( $57.4 \%$ vs. $43.8 \%$ ) though a majority of patients in both $\leq 40$ years and $>40$ years age groups reported it to be moderate in intensity ( $48.8 \%$ and $53.8 \%$ respectively).A very low percentage of both $\leq 40$ years and $>40$ years old patients gave a positive history of epistaxis (2.4\% and $3.4 \%$ respectively). A higher percentage of patients in $>40$ years age group reported an increase in urinary frequency $(45.5 \%$ vs. $30.6 \%)$ though a majority of patients in both $\leq 40$ years and $>40$ years age groups reported the change to be moderate $36.7 \%$ and $44.0 \%$ respectively). A higher percentage of patients in $>40$ years age group gave a positive history of nausea ( $25.4 \%$ vs. $20.5 \%)$, sleep apnea (38.6\% vs. $20.5 \%$ ), irregular heartbeat/palpitation $(39.9 \%$ vs. $33.0 \%)$, fatigue ( $74.8 \%$ vs. $67.0 \%)$ and confusion $(68.6 \%$ vs. $52.3 \%$ ) (Table 2).

Table 2: Descriptive Analysis: Age wise comparison

\begin{tabular}{|c|c|c|c|}
\hline \multirow{2}{*}{\multicolumn{2}{|c|}{ Variables }} & $\leq 40$ Years $(n=89)$ & $>40$ Years $(n=210)$ \\
\hline & & Frequency $(\%) /$ Mean \pm S.D. & Frequency $(\%) /$ Mean \pm S.D. \\
\hline \multirow{2}{*}{ Gender } & Male & $31(34.8)$ & $123(58.6)$ \\
\hline & Female & $58(65.2)$ & $87(41.4)$ \\
\hline \multirow{2}{*}{$\begin{array}{c}\text { Systolic Blood } \\
\text { Pressure }\end{array}$} & Normotensive/ Prehypertensive & $42(47.2)$ & $58(27.6)$ \\
\hline & Stage 1/Stage 2 Hypertensive & $47(52.8)$ & $152(72.4)$ \\
\hline \multirow{2}{*}{$\begin{array}{c}\text { Diastolic Blood } \\
\text { Pressure }\end{array}$} & Normotensive/ Prehypertensive & $45(50.5)$ & $105(50.0)$ \\
\hline & Stage $1 /$ Stage 2 Hypertensive & $44(49.5)$ & $105(50.0)$ \\
\hline \multicolumn{2}{|c|}{ Systolic Blood Pressure (mmHg) } & $137.69 \pm 14.70$ & $142.85 \pm 14.44$ \\
\hline \multicolumn{2}{|c|}{ Diastolic Blood Pressure (mmHg) } & $84.36 \pm 9.47$ & $85.46 \pm 10.57$ \\
\hline \multicolumn{2}{|c|}{ Hypertension Duration (Years) } & $2.85 \pm 3.74$ & $5.66 \pm 5.78$ \\
\hline \multirow{2}{*}{ Smoking } & Yes & $4(4.7)$ & $25(12.0)$ \\
\hline & No & $82(95.3)$ & $183(88.0)$ \\
\hline \multirow{2}{*}{ Headache } & Yes & $71(80.7)$ & $145(69.4)$ \\
\hline & No & $17(19.3)$ & $64(30.6)$ \\
\hline \multicolumn{2}{|c|}{ Headache Duration (Years) } & $1.87 \pm 0.64$ & $2.01 \pm 0.74$ \\
\hline \multirow{5}{*}{ Site of Headache } & Temporal & $7(10.1)$ & $16(11.1)$ \\
\hline & Parietal & $6(8.8)$ & $23(16.0)$ \\
\hline & Occipital & $19(27.5)$ & $28(19.4)$ \\
\hline & Frontal & $18(26.1)$ & $27(18.8)$ \\
\hline & Complete & $19(27.5)$ & $50(34.7)$ \\
\hline \multirow{2}{*}{$\begin{array}{l}\text { Intensity of } \\
\text { Headache }\end{array}$} & Mild & $23(32.9)$ & $30(20.7)$ \\
\hline & Severe & $22(31.4)$ & $47(32.4)$ \\
\hline
\end{tabular}


Prevalence of Clinical Signs and Symptoms of Hypertension: A Gender and Age Based Comparison

\begin{tabular}{|c|c|c|c|}
\hline \multirow{2}{*}{ Vertigo } & Yes & $41(47.7)$ & $121(59.3)$ \\
\hline & No & $45(52.3)$ & $83(40.7)$ \\
\hline \multirow{3}{*}{$\begin{array}{l}\text { Intensity of } \\
\text { Vertigo }\end{array}$} & Mild & $28(66.7)$ & $76(61.8)$ \\
\hline & Moderate & $12(28.6)$ & $38(30.9)$ \\
\hline & Severe & $2(4.8)$ & $9(7.3)$ \\
\hline \multirow{2}{*}{ Edema } & Yes & $33(40.2)$ & $84(42.6)$ \\
\hline & No & $49(59.8)$ & $113(57.4)$ \\
\hline \multirow{2}{*}{$\begin{array}{c}\text { Laterality of } \\
\text { Edema }\end{array}$} & Bilateral & $23(76.7)$ & $66(84.6)$ \\
\hline & Unilateral & $7(23.3)$ & $12(15.4)$ \\
\hline \multirow{3}{*}{$\begin{array}{c}\text { Grading of } \\
\text { Bilateral Edema }\end{array}$} & Mild & $6(17.1)$ & $20(23.0)$ \\
\hline & Moderate & $16(45.7)$ & $36(41.4)$ \\
\hline & Severe & $13(37.1)$ & $31(35.6)$ \\
\hline \multirow{2}{*}{ Chest Pain } & Yes & $28(32.2)$ & $101(49.3)$ \\
\hline & No & $59(67.8)$ & $104(50.7)$ \\
\hline \multirow{3}{*}{$\begin{array}{c}\text { Severity of Chest } \\
\text { Pain }\end{array}$} & Improves with rest & $13(48.2)$ & $39(38.6)$ \\
\hline & Needs pain relieving medication & $8(29.6)$ & $55(54.5)$ \\
\hline & Requires hospital visit & $6(22.2)$ & $7(6.9)$ \\
\hline \multirow{2}{*}{ Vision Problems } & Yes & $38(44.2)$ & $117(57.4)$ \\
\hline & No & $48(55.8)$ & $87(42.6)$ \\
\hline \multirow{4}{*}{$\begin{array}{c}\text { Type of Vision } \\
\text { Problem }\end{array}$} & Loss of central vision & $1(2.5)$ & $11(9.7)$ \\
\hline & Loss of peripheral vision & $11(28.2)$ & $23(20.4)$ \\
\hline & Dark spots in field of vision & $18(46.2)$ & $52(46.0)$ \\
\hline & Pain in eyes & $9(23.1)$ & $27(23.9)$ \\
\hline \multirow{2}{*}{ Dyspnea } & Yes & $39(43.8)$ & $117(57.4)$ \\
\hline & No & $50(56.2)$ & $87(42.6)$ \\
\hline \multirow{3}{*}{$\begin{array}{c}\text { Intensity of } \\
\text { Dyspnea }\end{array}$} & Mild & $9(22.0)$ & $18(15.4)$ \\
\hline & Moderate & $20(48.8)$ & $63(53.8)$ \\
\hline & Severe & $12(29.2)$ & $36(30.8)$ \\
\hline \multirow{2}{*}{ Epistaxis } & Yes & $2(2.4)$ & $7(3.4)$ \\
\hline & No & $83(97.6)$ & $200(96.6)$ \\
\hline \multirow{2}{*}{$\begin{array}{c}\text { Increased Urinary } \\
\text { Frequency }\end{array}$} & Yes & $26(30.6)$ & $92(45.5)$ \\
\hline & No & $59(69.4)$ & $110(54.5)$ \\
\hline \multirow{3}{*}{$\begin{array}{c}\text { Change in Urinary } \\
\text { Frequency }\end{array}$} & Mild & $10(33.3)$ & $32(32.0)$ \\
\hline & Moderate & $11(36.7)$ & $44(44.0)$ \\
\hline & Severe & $9(30.0)$ & $24(24.0)$ \\
\hline \multirow{2}{*}{ Nausea } & Yes & $18(20.5)$ & $53(25.4)$ \\
\hline & No & $70(79.5)$ & $156(74.6)$ \\
\hline \multirow{2}{*}{ Sleep Apnea } & Yes & $18(20.5)$ & $81(38.6)$ \\
\hline & No & $70(79.5)$ & $129(61.4)$ \\
\hline \multirow{2}{*}{$\begin{array}{c}\text { Irregular } \\
\text { Heartbeat/ } \\
\text { Palpitation }\end{array}$} & Yes & $29(33.0)$ & $83(39.9)$ \\
\hline & No & $59(67.0)$ & $125(60.1)$ \\
\hline \multirow{2}{*}{ Fatigue } & Yes & $59(67.0)$ & $157(74.8)$ \\
\hline & No & $29(33.0)$ & $53(25.2)$ \\
\hline & Yes & $46(52.3)$ & $144(68.6)$ \\
\hline
\end{tabular}




\section{Discussion}

The study results revealed that a much higher percentage of males were smokers though the most common site of headache was similar in both genders i.e. complete headache. A majority of males reported their headache to be of moderate intensity whereas a majority of females reported it to be of severe intensity. A higher percentage of males gave a positive history of chest pain though a higher percentage of females required a hospital visit for it to subside. A higher percentage of females gave a positive history of vision problems though the most common type of vision problem was dark spots in field of vision in both genders. A higher percentage of females gave a positive history of both fatigue and confusion.

The study results further revealed that a higher percentage of $>40$ years old patients were smokers whereas a higher percentage of $\leq 40$ years old patients gave a positive history of headache. The mean duration of headache was found to be higher in $>40$ years old patients though the most common sites of headache were occipital and complete in both age groups. A higher percentage of patients in $>40$ years age group gave a positive history of vertigo and chest pain though a higher percentage of $\leq 40$ years old patients required a hospital visit for their chest pain to subside. A higher percentage of $>40$ years old patients gave a positive history of vision problems though the most common type of vision problem was dark spots in field of vision in both age groups. A higher percentage of $>40$ years old patients gave a positive history of dyspnea and reported an increase in urinary frequency. A higher percentage of patients in $>40$ years age group gave a positive history of nausea, sleep apnea, irregular heartbeat/palpitation, fatigue and confusion as well.

The study results revealed that both males and females had almost equal levels of systolic and diastolic blood pressures, though Dustan HP in 1996 reported males to have higher blood pressure levels than females, albeit slightly. [11]Likewise, Daugherty SL et al., in 2011 also reported males to have lower rates of hypertension control than females. [12] This difference in findings could be a result of several factors, such as gender specific age structure and compliance rate of the populations in question. The study results further revealed that the patients in $>40$ years age group had higher levels of systolic and diastolic blood pressures, a finding well in line with published literature as Jo I et al., in 2001 also reported age to be associated with prevalence of hypertension. [13]

Moreover, a very high percentage of study participants gave a positive history of headache, irrespective of their gender or age. Similarly, D Tullio M et al., in 1988 also reported headache to be more prevalent in hypertensive than normotensive subjects. [14] Literature though reveals contrary findings as well as reported by Fuchs FD et al., in 2003 and Sherif SM et al., in 2012. [15,16] This difference in findings could well be attributed to different methodologies of the studies in question.

The study results further showed that vision problems were more prevalent among patients who were female or of older age in the study. Sherif SM et al., in 2012 did not report visual disturbances to be associated with hypertension, though without consideration for the gender or age of the study participants. [16] Furthermore, a higher percentage of $>40$ years old patients gave a positive history of dyspnea in the study. Karras DJ et al., in 2005 reported dyspnea to be associated with elevated blood pressure though irrespective of the age of the study participants. [17] Due to dearth of pertinent published literature, a meaningful comparison could not be made for the study findings mentioned above.

Moreover, a very low percentage of study participants gave a positive history of epistaxis, irrespective of their gender or age. Likewise, D Tullio M et al., in 1988 also did not find epistaxis to be associated with hypertension. [14]Furthermore, a very high percentage of study participants gave a positive history of fatigue, again irrespective of their gender or age. Unlike the study results though, D Tullio M et al., in 1988 did not report weakness to be associated with hypertension. [14]Due to lack of relevant published data, a comparison of the rest of study findings could not be made with the previous literature.

\section{Limitation and Recommendation}

It is acknowledged that being a cross-sectional study, recall bias may have affected the study results. Because of their potential to effect the clinical manifestation of hypertension, further evaluation of the role of gender and age in hypertension screening and management is recommended.

\section{Conclusion}

The study results revealed that the prevalence of smoking, chest pain, vision problems, fatigue and confusion were different between both genders. Furthermore, the prevalence of smoking, headache, vertigo, chest pain, vision problems, dyspnea, increased urinary frequency, nausea, sleep apnea, irregular heartbeat/ palpitation, fatigue and confusion were different between both age groups.

\section{Conflict of Interests}

The authors report no conflict of interests.

\section{References}

1. He J, Whelton PK. Epidemiology and prevention of hypertension. Med Clin North Am. 1997; 81(5):1077-1097.

2. Whelton PK. Epidemiology of hypertension. Lancet. 1994; 344(8915):101-106.

3. World Health Day. WHO; 2013.

4. Ezzati M, Lopez AD, Rodgers A, Vander Hoorn S, Murray CJ, Comparative Risk Assessment Collaborating Group. Selected major risk factors and global and regional burden of disease. Lancet. 2002; 360(9343):1347-1360. DOI:10.1016/S0140-6736(02)11403-6

5. Kearney PM, Whelton M, Reynolds K, Muntner P, Whelton PK, He J. Global burden of hypertension: analysis of worldwide data. Lancet. 2005; 365(9455):217-223. DOI:10.1016/S0140-6736(05)17741-1

6. Neupane D, McLachlan CS, Sharma R, Gyawali B, Khanal V, Mishra SR, et al. Prevalence of hypertension in member countries of South Asian Association for Regional Cooperation (SAARC): systematic review 
and meta-analysis. Medicine. 2014; 93(13): e74. DOI:10.1097/ MD.0000000000000074

7. Non communicable Diseases Country Profile 2014. World Health Organization. 2014.

8. Roger VL, Go AS, Lloyd-Jones DM, Benjamin EJ, Berry JD, Borden WB et al. Heart disease and stroke statistics-2012 update: a report from the American Heart Association. Circulation. 2012; 125(1):e2-220. DOI: 10.1161/CIR.0b013e31823ac046

9. Messerli FH, Williams B, Ritz E. Essential hypertension. Lancet. 2007; 370(9587):591-603. DOI:10.1016/S0140-6736(07)61299-9

10. Mancia G, Fagard R, Narkiewicz K, Redon J, Zanchetti A, Böhm M, et al. $2013 \mathrm{ESH} / \mathrm{ESC}$ guidelines for the management of arterial hypertension: the Task Force for the Management of Arterial Hypertension of the European Society of Hypertension (ESH) and of the European Society of Cardiology (ESC). Blood pressure. 2013; 22(4):193-278. DOI:10.1097/01.hjh.0000431740.32696.cc

11. Dustan HP. Gender differences in hypertension. J Hum Hypertens 1996;10(6):337-340.

12. Daugherty SL, Masoudi FA, Ellis JL, Ho PM, Schmittdiel JA, Tavel HM, et al. Age dependent gender differences in hypertension management. Journal of hypertension. 2011; 29(5):1005-1011. DOI:10.1097/ HJH.0b013e3283449512
13. Jo I, Ahn Y, Lee J, Shin KR, Lee HK, Shin C. Prevalence, awareness, treatment, control and risk factors of hypertension in Korea: the Ansan study. Journal of hypertension. 2001; 19(9):1523-1532.

14. Di Tullio M, Alli C, Avanzini F, Bettelli G, Colombo F, Devoto MA, et al. Prevalence of symptoms generally attributed to hypertension or its treatment: study on blood pressure in elderly outpatients (SPAA). Journal of hypertension. Supplement: official journal of the International Society of Hypertension. 1988; 6(1):S87-90.

15. Fuchs FD, Gus M, Moreira LB, Moreira WD, Goncalves SC, Nunes G. Headache is not more frequent among patients with moderate to severe hypertension. Journal of human hypertension. 2003;17(11):787-790. DOI: 10.1038/sj.jhh.1001621

16. Sherif SM, Ahmed ME, Homeida MM. Prevalence of hypertension in an urban community in Sudan. Khartoum Medical Journal. 2008;1(2): 72-74.

17. Karras DJ, Ufberg JW, Harrigan RA, Wald DA, Botros MS, McNamara RM. Lack of relationship between hypertension-associated symptoms and blood pressure in hypertensive ED patients. Am J Emerg Med. 2005; 23(2):106-110. 